\title{
Phylogenetic study and multiplex PCR-based detection of Burkholderia plantarii, Burkholderia glumae and Burkholderia gladioli using gyrB and rpoD sequences
}

\author{
Correspondence \\ Yasufumi Hikichi \\ yhikichi@cc.kochi-u.ac.jp
}

\author{
Yukiko Maeda, ${ }^{1}$ Hirosuke Shinohara, ${ }^{2}$ Akinori Kiba, ${ }^{1}$ Kouhei Ohnishi, ${ }^{3}$ \\ Naruto Furuya, ${ }^{4}$ Yoshiaki Kawamura, ${ }^{5}$ Takayuki Ezaki, ${ }^{5}$ Peter Vandamme, \\ Seiya Tsushima ${ }^{7}$ and Yasufumi Hikichi ${ }^{1}$
1,3 Laboratory of Plant Pathology and Biotechnology ${ }^{1}$ and Research Institute of Molecular Genetics $^{3}$, Kochi University, 200 Monobe, Nankoku, Kochi 783-8502, Japan
${ }^{2}$ National Agricultural Research Center for Tohoku Region, Fukushima 960-2156, Japan
${ }^{4}$ Laboratory of Plant Pathology, Kyushu University, Fukuoka 812-8581, Japan
${ }^{5}$ Department of Microbiology, Gifu University Graduate School of Medicine, Gifu 501-1194, Japan
${ }^{6}$ Laboratorium voor Microbiologie, Universiteit Gent, B-9000 Gent, Belgium
${ }^{7}$ National Institute for Agro-Environmental Science, Tsukuba, Ibaraki 305-8604, Japan

\section{INTRODUCTION}

Bacterial seedling rot (Uematsu et al., 1976) and seedling blight (Azegami et al., 1987) caused by Burkholderia glumae and Burkholderia plantarii, respectively, are devastating diseases of rice seedling cultivation in nursery boxes. During germination, these pathogens infect seeds and invade plumules through stomata and wounds and proliferate in the intercellular spaces of the parenchyma (Azegami et al., 1988; Hikichi et al., 1995). Proliferation of B. glumae and B. plantarii in the plumules leads to production of the toxic materials toxoflavin (Sato et al., 1989; Yoneyama et al., 1998)

Published online ahead of print on 31 December 2005 as DOI 10.1099/ijs.0.64184-0.

The GenBank/EMBL/DDBJ accession numbers for the gyrB and $r p o D$ gene sequences determined in this study are given in Table 1. and tropolone (Azegami et al., 1985), resulting in rot and blight in rice seedlings, respectively.

Within Burkholderia gladioli, three pathovars, all of which are recognized as phytopathogenic bacteria, have been delineated: B. gladioli pv. gladioli, which causes gladiolus rot (Hildebrand et al., 1973); B. gladioli pv. alliicola, which causes onion bulb rot (Young et al., 1978); and B. gladioli pv. agaricicola, which causes rapid soft rot of cultivated mushrooms (Lincoln et al., 1991). B. gladioli has also been isolated from rice seedlings showing bleaching symptoms, suggesting that this bacterium also infects rice seedlings (Kato et al., 1992). On the other hand, proliferation of B. glumae and $B$. plantarii is suppressed in rice seeds infected with $B$. gladioli (Miyagawa, 2000). Therefore, ecological studies on B. gladioli in rice plants are important to understand disease development caused not only by $B$. gladioli but also by 
B. glumae and B. plantarii. Such ecological studies require efficient detection and identification of these three ricepathogenic Burkholderia species. Although the diversity of Burkholderia species has been analysed using 16S rRNA gene sequences (Hu et al., 2001; Salles et al., 2002), the discriminatory power of this gene is too restricted to reveal the detailed phylogenetic relationships among $B$. plantarii, $B$. glumae and B. gladioli. The $16 \mathrm{~S}$ rRNA gene has been widely used for designing taxonomically meaningful, highly specific PCR primers, providing enough sequence information to allow the analysis of both close and distant phylogenic relationships among micro-organisms (Stackebrandt \& Goebel, 1994). However, the degree of resolution obtained with 16S rRNA gene sequence analysis is not sufficiently discriminatory to permit resolution of intrageneric relationships among closely related micro-organisms, because of the extremely slow rate of evolution of the 16S rRNA gene (Yamamoto \& Harayama, 1998). The genes encoding the $\beta$-subunit polypeptide of DNA gyrase ( gyr $B)$ and $\sigma^{70}$ factor $(r p o D)$ are estimated to evolve much faster than the $16 \mathrm{~S}$ rRNA gene (Yamamoto \& Harayama, 1998).

In the present study, we analysed the phylogenetic diversity in the gyrB and $r p o D$ gene sequences of these three ricepathogenic Burkholderia species, in order to develop a specific and sensitive detection method.

\section{METHODS}

Bacteria and DNA preparation. Six Burkholderia species with validly published names, comprising a total of 108 strains, including 41 strains of B. glumae, 24 strains of B. plantarii and 37 strains of $B$. gladioli, were examined in this study (Table 1). Each bacterial isolate was grown aerobically in nutrient broth at $30{ }^{\circ} \mathrm{C}$. Chromosomal DNA from the bacteria used as the PCR template was prepared using an AquaPure Genomic DNA Isolation kit (Bio-Rad), according to the supplier's instructions.

PCR amplification and sequencing of gyrB and rpoD. PCR of gyrB and $r p o D$ was performed using primers UP-1E and AprU, and 70F2 and 70R2, respectively, as shown in Table 2. PCR was performed with a thermal cycler (TaKaRa) using PCR buffer (TaKaRa) containing $200 \mu \mathrm{M}$ of each of the dNTPs, $0.5 \mu \mathrm{M}$ of each primer, $0.2 \mu \mathrm{g}$ template DNA and $2.5 \mathrm{U}$ Ex-Taq polymerase (TaKaRa), in a total volume of $40 \mu \mathrm{l}$. A total of 35 amplification cycles were performed with template DNA denaturation at $94^{\circ} \mathrm{C}$ for $1 \mathrm{~min}$, primer annealing at $58{ }^{\circ} \mathrm{C}$ for $1 \mathrm{~min}$ and primer extension at $72{ }^{\circ} \mathrm{C}$ for $1 \mathrm{~min}$. PCR products were electrophoresed on $1.0 \%$ agarose gels and purified using Quantum Prep Freeze 'N Squeeze DNA Gel Extraction spin columns (Bio-Rad), following the manufacturer's instructions. The nucleotide sequences of $g y r B$ and $r p o D$ were determined directly from the PCR fragments using primers M13R (5'CAGGAAACAGCTATGACC-3') and M13(-21) (5'-TGTAAAACGACGGCCAGT-3'), and 70Fs (5'-ACGACTGACCCGGTACGCATGTA$\left.3^{\prime}\right)$ and 70Rs (5'-ATAGAAATAACCAGACGTAAGTT-3'), respectively. Sequencing was carried out using an ABI Automated DNA Sequencer model 373 (Applied Biosystems) and analysed using DNASIS-Mac software (Hitachi Software Engineering).

Data analysis. The nucleotide sequences of $\operatorname{gyrB}(768-801 \mathrm{bp})$ and $r p o D$ (807-834 bp) genes were aligned and a phylogenetic tree was constructed using CLUSTAL W (DNA database of Japan; http:// www.ddbj.nig.ac.jp/search/clustalw-j.html) with the neighbour-joining method (Saitou \& Nei, 1987), using genetic distances computed with Kimura's two-parameter model (Kimura, 1980). The neighbourjoining phylogenetic tree was drawn using TreeView. The nucleotide sequences of $g y r B$ and $r p o D$ from Escherichia coli $\mathrm{K}-12$ were used as the outgroup for phylogenetic tree reconstructions.

Analysis of the phylogenetic diversity of B. plantarii strains. Aliquots $(40 \mu \mathrm{l})$ of each PCR product from the genomic DNA of B. plantarii strains obtained using primers UP-1E and AprU were ethanol-precipitated and the pellets were dissolved in $10 \mu \mathrm{l}$ distilled water. The DNA in the solutions was digested with SacI and HaeII (both from TaKaRa) at $37^{\circ} \mathrm{C}$ for $6 \mathrm{~h}$, loaded onto horizontal $1.2 \%$ TAE agarose gels and stained with ethidium bromide after electrophoresis for detection of specific DNA fragments corresponding to the $\operatorname{gyrB}$ nucleotide sequences of the strains.

Multiplex PCR. To detect and discriminate B. plantarii, B. glumae and B. gladioli using single-step PCR, primers (Table 2) developed for the $\operatorname{gyr} B$ gene of the bacteria were used for development of a multiplex-PCR protocol. PCR was performed with one cycle of $94^{\circ} \mathrm{C}$ for $2 \mathrm{~min}$ and 35 cycles of $94^{\circ} \mathrm{C}$ for $1 \mathrm{~min}, 63^{\circ} \mathrm{C}$ for $1 \mathrm{~min}$ and $72{ }^{\circ} \mathrm{C}$ for $1 \mathrm{~min}$. Aliquots $(9 \mu \mathrm{l})$ of each PCR product were loaded onto horizontal $1.5 \%$ TAE agarose gels and stained with ethidium bromide after electrophoresis for detection of 597, 529 and $479 \mathrm{bp}$ DNA fragments corresponding to the gyrB nucleotide sequences of B. plantarii, B. glumae and B. gladioli, respectively.

Analysis of rice seeds infected with B. plantarii, B. glumae and $\boldsymbol{B}$. gladioli. To test whether infection of rice seeds with $B$. plantarii, B. glumae and B. gladioli could be detected using multiplex $\mathrm{PCR}$, rice seeds naturally infected with $B$. plantarii and B. glumae were obtained from Dr H. Miyagawa, National Agricultural Research Center for Western Region, Japan. Flowering spikelets of rice plants cultivated in pots were inoculated with a suspension of $B$. plantarii MAFF 302391, MAFF 302907, MAFF 302924, MAFF 311030 or MAFF $301723^{\mathrm{T}}$, B. glumae MAFF $301169^{\mathrm{T}}$ or B. gladioli MAFF 302386, MAFF 302543, MAFF 302918, MAFF 302919 or T-1 at $1.0 \times 10^{8}$ c.f.u. $\mathrm{ml}^{-1}$ by spray application at $10 \mathrm{ml}$ per plant, and the resultant rice seeds infected with each strain were used in this study. Non-infected rice seeds were used as a control. One gram of rice seeds was ground in a mortar with $1.0 \mathrm{ml}$ distilled water and the suspension was then placed in a microtube and centrifuged at $1000 \mathrm{~g}$ for $1 \mathrm{~min}$. The supernatant was held at $100^{\circ} \mathrm{C}$ for $8 \mathrm{~min}$ and then centrifuged at $12000 \mathrm{~g}$ for $3 \mathrm{~min}$. Twenty-five microlitres of the supernatant was used as a template for the multiplex PCR.

\section{RESULTS AND DISCUSSION}

\section{Phylogenetic diversity of B. plantarii, B. glumae and B. gladioli}

The phylogeny of six plant-pathogenic Burkholderia species (Burkholderia andropogonis, Burkholderia caryophylli, Burkholderia cepacia, B. plantarii, B. glumae and B. gladioli) was analysed using the combined nucleotide sequences of the gyrB and $r p o D$ genes. These species all represented different clusters in the resulting phylogenetic tree (Fig. 1). The combined gyrB and $r p o D$ nucleotide sequences showed high similarity and the sequence similarity between $B$. glumae MAFF $301169^{\mathrm{T}}$ and B. plantarii MAFF $301723^{\mathrm{T}}$ was $96 \cdot 2 \%$, indicating a close phylogenetic relationship between the two species. Furthermore, the B. plantarii, B. glumae and $B$. gladioli clusters were supported by high bootstrap probabilities, indicating that they each form a tight monophylogenetic branch (Fig. 1). 
Table 1. Burkholderia strains analysed and classifications established according to nucleotide sequences of $g y r B$ and $r p o D$

ATCC, American Type Culture Collection; GTC, Gifu Type Culture Collection, Japan; KU, Kyushu University, Japan; KUCS, Kochi University, Japan; LMG, BCCM/LMG Bacteria Collection, Laboratorium voor Microbiologie, Gent, Belgium; MAFF, Micro-organisms Section of the MAFF Gene Bank.

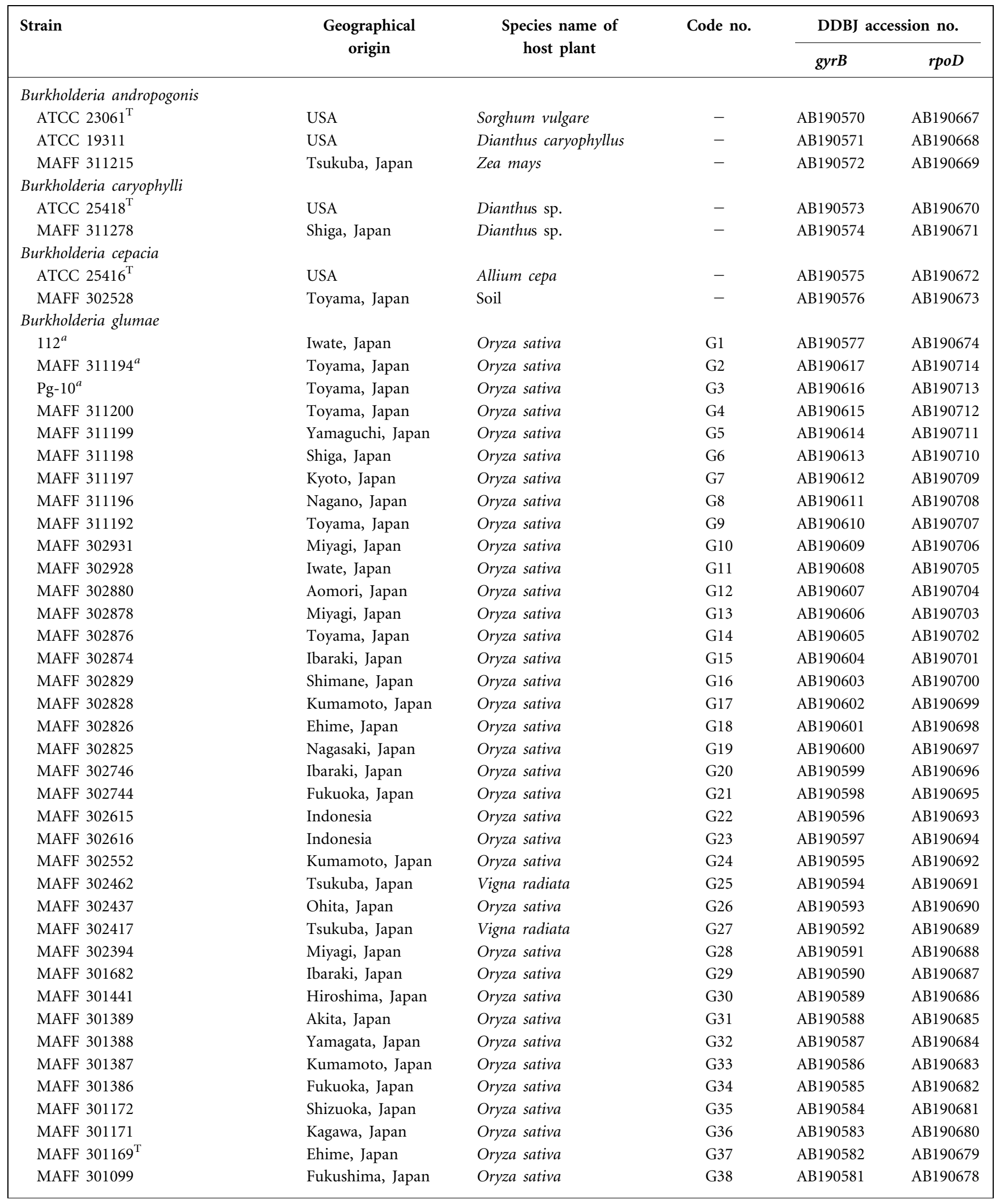


Table 1. cont.

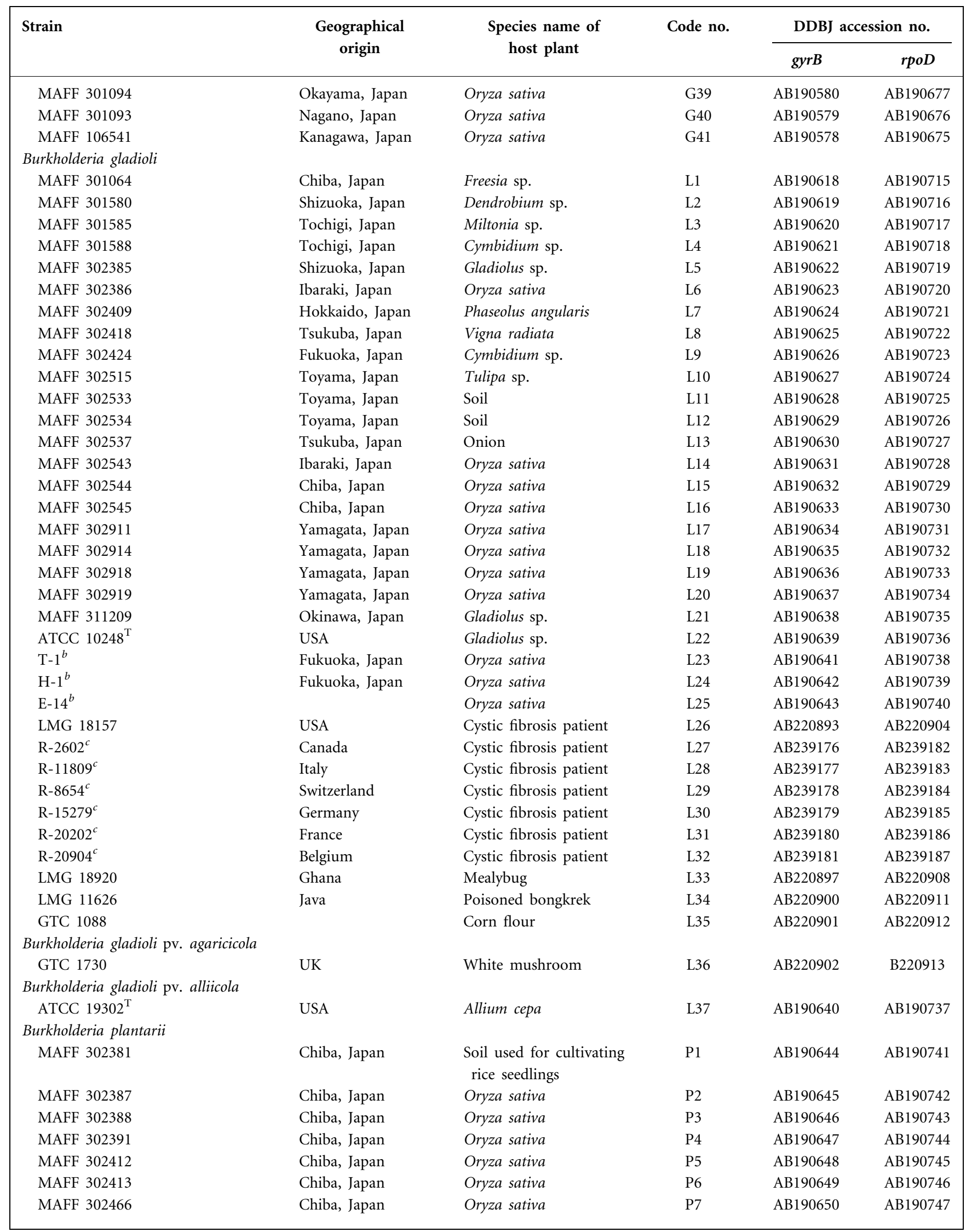


Table 1. cont.

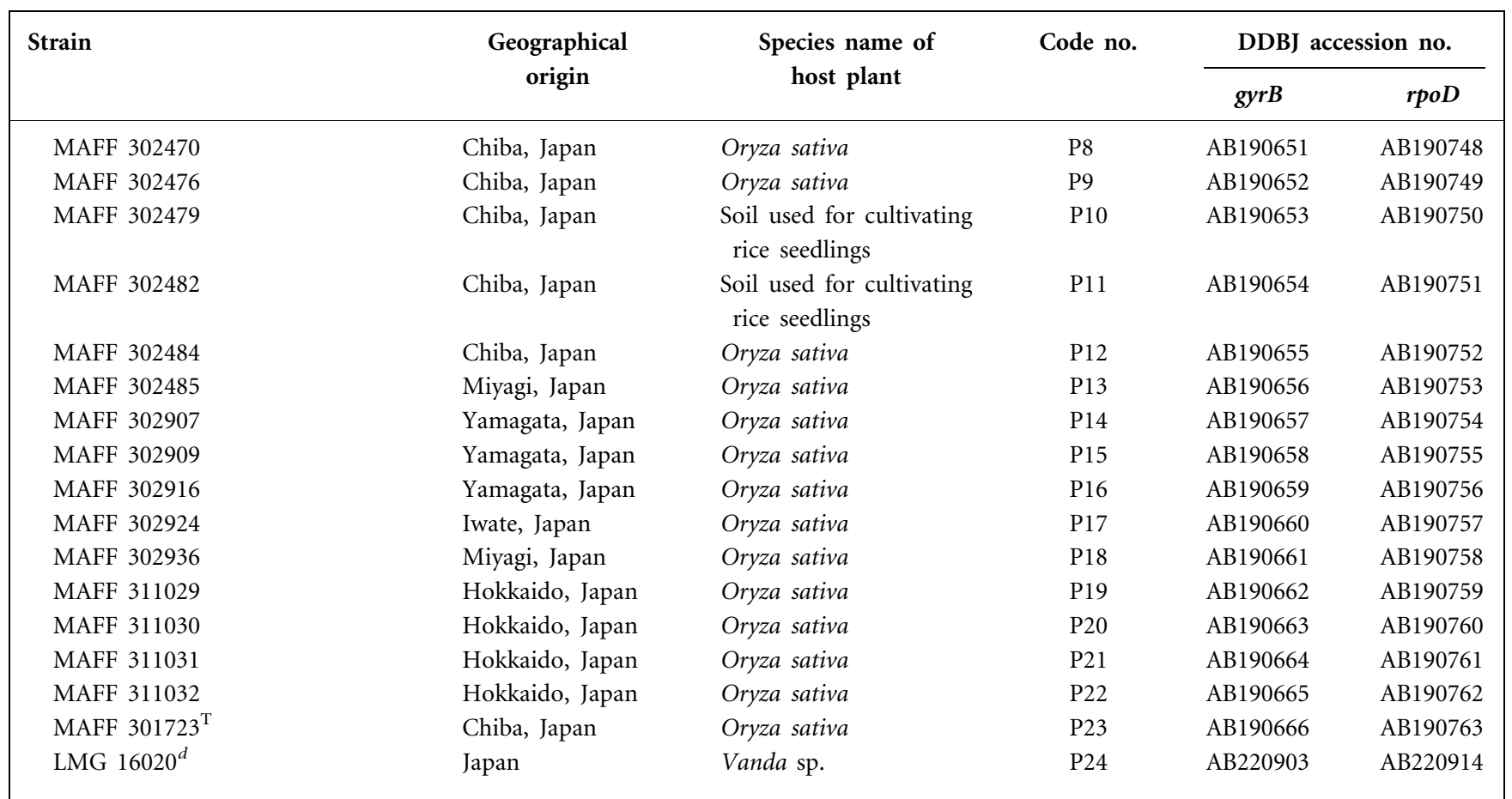

${ }^{*}$ Source of strain: $a$, KUCS; $b, \mathrm{KU} ; c, \mathrm{LMG} ; d$, ATCC.

\section{Phylogenetic relationships among B. plantarii strains}

Twenty-three of 24 B. plantarii isolates from Japan were from rice seedlings and soil used for cultivating rice seedlings in Chiba, Miyagi, Iwate and Yamagata (located in the northern part of the main island of Japan) and in Hokkaido (Fig. 2). The remaining strain, LMG 16020, is the type strain of $B$. vandii that is now classified as a strain of $B$. plantarii (Coenye et al., 1999). Whereas the Vanda strain LMG 16020 occupied a distinct position in the tree, the 23 rice strains were divided into three subgroups (Fig. 1). Nucleotide sequences of the gyrB PCR products from strains in subgroup I showed one restriction site for both HaeII and SacI (data not shown). One restriction site for HaeII was located in the $g y r B$ PCR products from strains in subgroup II. No HaeII and SacI restriction sites were present in the gyrB PCR products from strains in subgroup III. SacI and Haell digestion of the gyrB PCR products allowed discrimination of strains among subgroups I, II and III (Fig. 2).

Table 2. PCR and sequencing primers used in this study

N, any; R, A or G; S, C or G; Y, C or T; M, A or C.

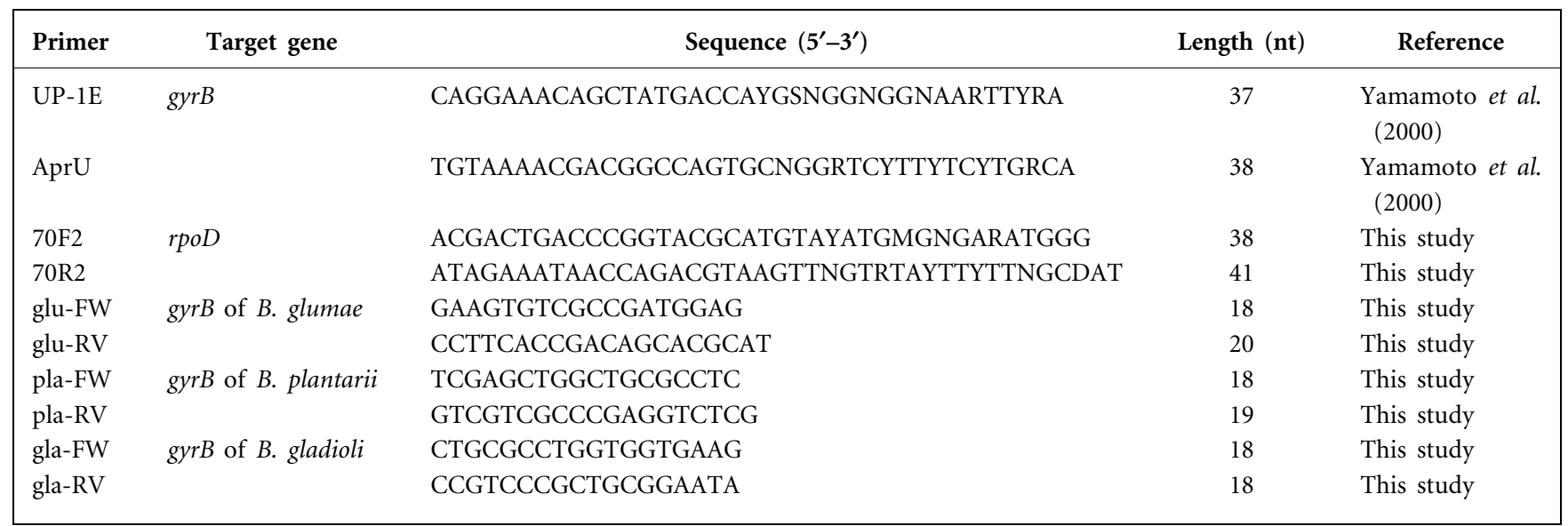




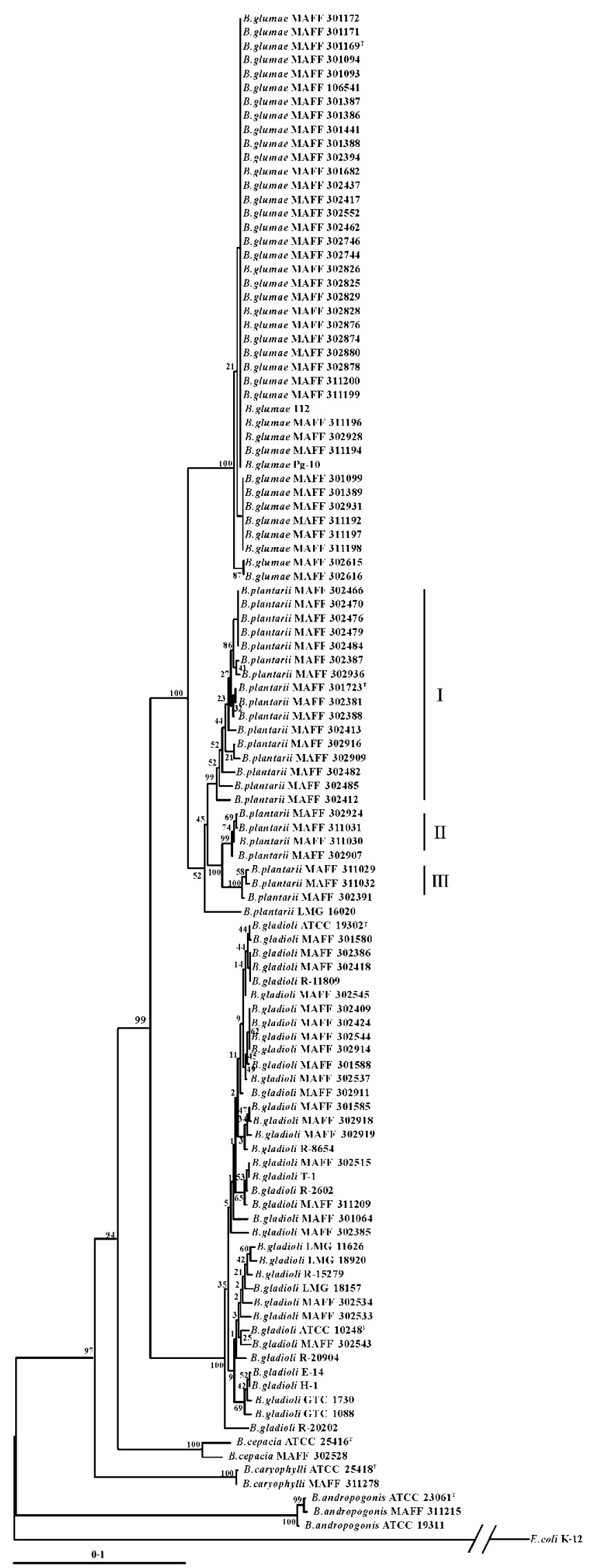

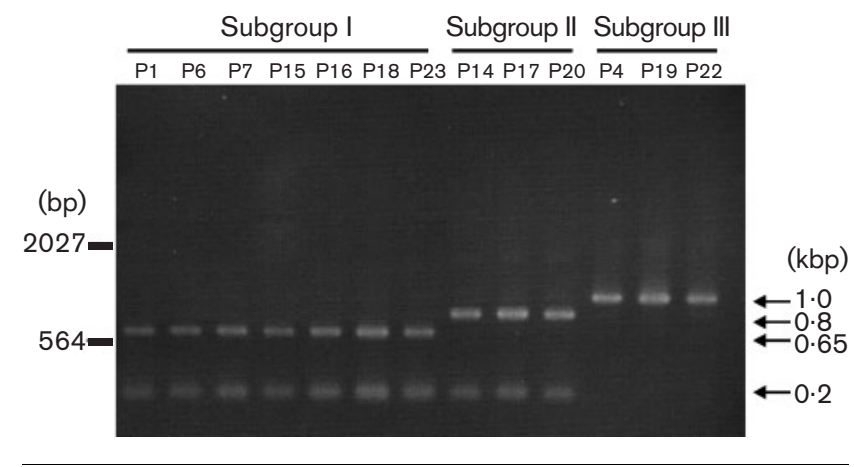

Fig. 2. Ethidium bromide-stained gel of Haell- and Sacldigested partial fragments of gyrB amplified by PCR from $B$. plantarii strains using primers UP-1E and AprU. See Table 1 and Fig. 1, respectively, for strain numbers and subgroups.

\section{Phylogenetic relationships among B. glumae strains}

Analysis of combined nucleotide sequences of the $\operatorname{gyr} B$ qnd $r p o D$ genes showed no diversity among 41 strains of $B$. glumae. The nucleotide sequences of gyrB in all 41 strains were identical and those of $r p o D$ in six Japanese strains and two Indonesian strains differed by only one and two nucleotides, respectively, compared with those of the other 33 strains (data not shown). These results indicate that the diversity of nucleotide sequences of $g y r B$ and $r p o D$ among B. glumae strains is very restricted.

\section{Phylogenetic relationships among B. gladioli strains}

B. gladioli R-20202, which was obtained from a specimen from a cystic fibrosis patient in France, occupied a unique position among the 37 B. gladioli strains examined (Fig. 1). All other isolates formed a rather loose assemblage without subdivision supported by high bootstrap values. The combined nucleotide sequences of gyrB and $r p o D$ of two rice strains, MAFF 302544 and MAFF 302914, were identical to those of the mung bean strain MAFF 302409 and the Cymbidium strain MAFF 302424. Furthermore, those of strain T-1 were identical to those of the Tulip strain MAFF 302515. Moreover, the combined translated amino acid sequences of $g y r B$ and $r p o D$ of the rice strains MAFF 302543, E-14 and H-1 were identical not only to those of the corn

Fig. 1. Phylogenetic tree of Burkholderia species based on the combined nucleotide sequences of gyrB and $r p o D$ genes constructed with CLUSTAL W (DNA Database of Japan; http:// www.ddbj.nig.ac.jp/search/clustalw-j.html) using the neighbourjoining method (Saitou \& Nei, 1987). Bar, 0.1 substitutions per position. Numbers at nodes represent percentage bootstrap values of 1000 resamplings. Sequences from E. coli K-12 were used as the outgroup. 
flour strain GTC 1088, B. gladioli pv. agaricicola GTC 1730, the gladiolus strain ATCC $10248^{\mathrm{T}}$ and soil strains MAFF 302533 and MAFF 302534, but also to the cystic fibrosis patient strains LMG 18157 (USA) and R-15279 (Germany). These results indicate that the pathovar, host plant and geographical origin of the strains correlate poorly with the phylogenetic diversity among the B. gladioli strains.

\section{Detection of B. gladioli, B. glumae and $B$. plantarii in infected rice seeds by multiplex PCR}

A multiplex PCR-based detection method for B. gladioli, B. glumae and B. plantarii was developed using the gyrB nucleotide sequences (Table 2). A 479 bp fragment specific for B. gladioli was amplified from the genomic DNA of all B. gladioli strains used in this study (Fig. 3). From the genomic DNA of all B. glumae strains tested, a 529 bp DNA fragment was specifically amplified in the multiplex PCR. A 597 bp DNA fragment was specifically amplified from the genomic DNA of all B. plantarii strains tested, including LMG 16020 from Vanda sp. No DNA fragments were amplified from the genomic DNA of B. cepacia ATCC $25416^{\mathrm{T}}$. Sequencing of the PCR products confirmed the specificity of the multiplex PCR (data not shown).

To assess the usefulness of multiplex PCR in discriminatory detection of rice seeds infected with $B$. gladioli, B. glumae and B. plantarii, DNA isolated from pathogen-infected rice seeds was used as a template. A $479 \mathrm{bp}$ fragment specific for B. gladioli was only amplified from DNA of rice seeds from plants inoculated with B. gladioli MAFF 302386, MAFF 302543, MAFF 302918, MAFF 302919 and T-1 (Fig. 4a). One fragment of $529 \mathrm{bp}$ in length was amplified from DNA of rice seeds from plants inoculated with B. glumae MAFF $301169^{\mathrm{T}}$. A 597 bp DNA fragment was amplified from DNA of rice seeds from plants inoculated with $B$. plantarii MAFF 302391, MAFF 302907, MAFF 302924, MAFF 311030 and MAFF $301723^{\mathrm{T}}$. Furthermore, two fragments of 529 and $597 \mathrm{bp}$ in length were amplified from DNA of rice seeds naturally infected with B. glumae and B. plantarii, respectively (Fig. $4 \mathrm{~b}$ ). Sequencing of the PCR products

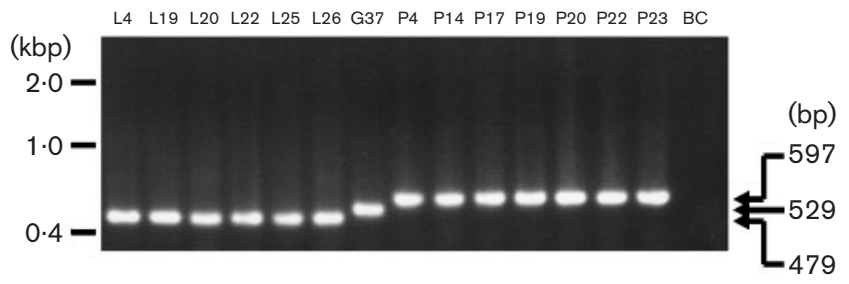

Fig. 3. Sensitive detection of $B$. plantarii, B. glumae and $B$. gladioli by multiplex PCR. The expected sizes of partial fragments of gyrB amplified by PCR from genomic DNA of B. plantarii, B. glumae and B. gladioli were 597, 529 and $479 \mathrm{bp}$, respectively. See Table 1 for strain numbers. BC, B. cepacia ATCC $25416^{\top}$.

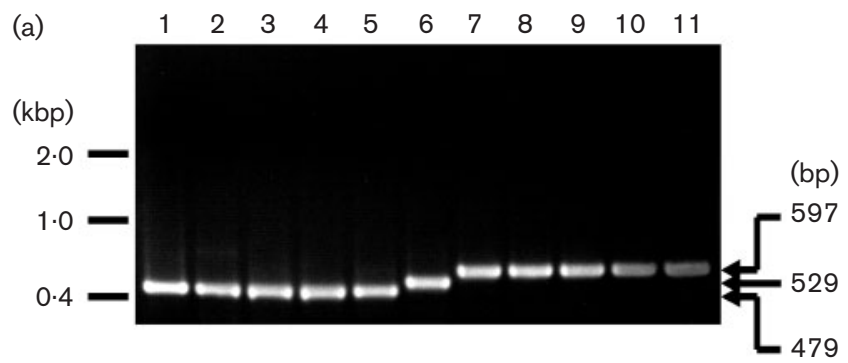

(b)

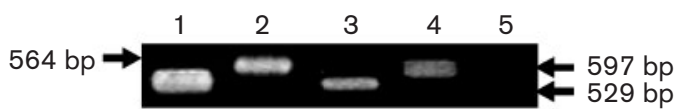

Fig. 4. Detection of B. plantarii, B. glumae and B. gladioli in rice seeds by multiplex PCR. The expected sizes of partial fragments of gyrB amplified by PCR from DNA isolated from rice seeds infected with $B$. plantarii, B. glumae and B. gladioli were 597, 529 and $479 \mathrm{bp}$, respectively. (a) PCR products from DNA of rice seeds produced from rice plants inoculated with B. plantarii, B. glumae or B. gladioli. Lanes: $1-5$, B. gladioli MAFF 302386, MAFF 302543, MAFF 302918, MAFF 302919 and T-1, respectively; $6, B$. glumae MAFF $301169^{\top} ; 7-11, B$. plantarii MAFF 302391, MAFF 302907, MAFF 302924, MAFF 311030 and MAFF $301723^{\top}$, respectively. (b) Lanes: 1 and 2, PCR products from DNA of rice seeds naturally infected with $B$. glumae and $B$. plantarii, respectively; 3 and 4, PCR products from genomic DNA of $B$. glumae MAFF $301169^{\top}$ and $B$. plantarii MAFF $301723^{\top}$, respectively; 5, PCR products from DNA of non-infected rice seeds.

confirmed the specificity obtained by PCR (data not shown). No products were obtained from DNA from non-infected rice seeds (Fig. $4 \mathrm{~b}$ ). These results show that the multiplexPCR protocol facilitates specific detection and discrimination of rice seeds infected with B. plantarii, B. glumae and B. gladioli.

Many ecological studies on B. glumae and B. plantarii have been reported, leading to the development of systems to control the diseases caused by these two Burkholderia species. However, the ecology and pathogenicity mechanism of $B$. gladioli on rice plants remain unclear. Moreover, the antagonistic activity of B. gladioli against B. glumae and $B$. plantarii in rice plants (Miyagawa, 2000) shows that an understanding of the ecology of B. gladioli on rice plants would facilitate not only the development of control systems for B. gladioli-induced disease, but also an understanding of the ecology of B. glumae and B. plantarii on rice plants. In the present study, we have designed a multiplex PCR that can be used for the simultaneous detection of $B$. plantarii, B. glumae and B. gladioli in rice seeds infected with these Burkholderia species. Therefore, this assay might facilitate an understanding of the ecological significance of Burkholderia species, especially the interactions that control their survival fitness on rice plants, thus leading to the development of relevant control systems. 


\section{ACKNOWLEDGEMENTS}

This work was supported financially by a grant from Sumitomo Chemical Co. Ltd and a Grant-in Aid for Scientific Research (no. 16658020) from the Japanese Society for the Promotion of Sciences to Y. H. and by a Sasakawa Scientific Research Grant from the Japan Science Society to Y. M.

\section{REFERENCES}

Azegami, K., Nishiyama, K., Watanabe, Y., Suzuki, T., Yoshida, M., Nose, K. \& Toda, S. (1985). Tropolone as a root growth inhibitor produced by a plant pathogenic Pseudomonas sp. causing seedling blight of rice. Ann Phytopathol Soc Jpn 51, 315-317.

Azegami, K., Nishiyama, K., Watanabe, Y., Kadota, I., Ohuchi, A. \& Fukazawa, C. (1987). Pseudomonas plantarii sp. nov., the causal agent of rice seedling blight. Int J Syst Bacteriol 37, 144-152.

Azegami, K., Nishiyama, K. \& Tabei, H. (1988). Infection counts of rice seedlings with Pseudomonas plantarii and Pseudomonas glumae. Ann Phytopathol Soc Jpn 54, 337-341.

Coenye, T., Holmes, B., Kersters, K., Govan, J. R. W. \& Vandamme, P. (1999). Burkholderia cocovenenans (van Damme et al. 1960) Gillis et al. 1995 and Burkholderia vandii Urakami et al. 1994 are junior synonyms of Burkholderia gladioli (Severini 1913) Yabuuchi et al. 1993 and Burkholderia plantarii (Azegami et al. 1987) Urakami et al. 1994, respectively. Int J Syst Bacteriol 49, 37-42.

Hikichi, Y., Okuno, T. \& Furusawa, I. (1995). Mode of action of oxolinic acid against bacterial seedling rot of rice caused by Pseudomonas glumae. III. Infection with P. glumae into plumules. Ann Phytopathol Soc Jpn 61, 134-136.

Hildebrand, D. C., Palleroni, N. J. \& Doudoroff, M. (1973). Synonymy of Pseudomonas gladioli Severini 1913 and Pseudomonas marginata (McCulloch 1921) Stapp 1928. Int J Syst Bacteriol 23, 433-437.

Hu, F.-P., Young, J. M., Triggs, C. M., Park, D.-C. \& Saul, D. J. (2001). Relationships within the Proteobacteria of plant pathogenic Acidovorax species and subspecies, Burkholderia species, and Herbaspirillum rubrisubalbicans by sequence analysis of $16 \mathrm{~S}$ rDNA, numerical analysis and determinative tests. Antonie van Leeuwenhoek 80, 201-213.

Kato, T., Tanaka, T. \& Fujita, Y. (1992). Studies on bacterial seedling blight of rice. 1. Classification of bacteria, obtained from diseased seedling of rice in Yamagata prefecture. Bull Yamagata Agric Exp Stn 26, 103-109 (in Japanese).

Kimura, M. (1980). A simple method for estimating evolutionary rates of base substitutions through comparative studies of nucleotide sequences. J Mol Evol 16, 111-120.

Lincoln, S. P., Fermor, T. R., Stead, D. E. \& Sellwood, J. E. (1991). Bacterial soft rot of Agaricus bitorquis. Plant Pathol 40, 136-144.

Miyagawa, H. (2000). Biocontrol of bacterial seedling blight of rice caused by Burkholderia gladioli using with its avirulent isolate. Jpn J Phytopathol 66, 232-238 (in Japanese).

Saitou, N. \& Nei, M. (1987). The neighbor-joining method: a new method for reconstructing phylogenetic trees. Mol Biol Evol 4, 406-425.

Salles, J. F., De Souza, F. A. \& van Elsas, J. D. (2002). Molecular method to assess the diversity of Burkholderia species in environmental samples. Appl Environ Microbiol 68, 1595-1603.

Sato, Z., Koiso, Y., Iwasaki, S., Matsuda, I. \& Shirata, A. (1989). Toxins produced by Pseudomonas glumae. Ann Phytopathol Soc Jpn 55, 353-356 (in Japanese).

Stackebrandt, E. \& Goebel, B. M. (1994). Taxonomic note: a place for DNA-DNA reassociation and 16S rRNA sequence analysis in the present species definition in bacteriology. Int J Syst Bacteriol 44, 846-849.

Uematsu, T., Yoshimura, D., Nishiyama, K., Ibaraki, T. \& Fujii, H. (1976). Pathogenic bacterium causing seedling rot of rice. Ann Phytopathol Soc Jpn 42, 464-471 (in Japanese).

Yamamoto, S. \& Harayama, S. (1998). Phylogenetic relationships of Pseudomonas putida strains deduced from the nucleotide sequences of gyrB, rpoD and 16S rRNA genes. Int J Syst Bacteriol 48, 813-819. Yamamoto, S., Kasai, H., Arnold, D. L., Jackson, R. W., Vivian, A. \& Harayama, S. (2000). Phylogeny of the genus Pseudomonas: intrageneric structure reconstructed from the nucleotide sequences of gyrB and rpoD genes. Microbiology 146, 2385-2394.

Yoneyama, K., Kono, Y., Yamaguchi, I., Horikoshi, M. \& Hirooka, T. (1998). Toxoflavin is an essential factor for virulence of Burkholderia glumae causing rice seedling rot disease. Ann Phytopathol Soc Jpn 64, 91-96.

Young, J. M., Dye, D. W., Bradbury, J. F., Panagopoulos, C. G. \& Robbs, C. F. (1978). A proposed nomenclature and classification for plant pathogenic bacteria. N Z J Agric Res 21, 153-177. 